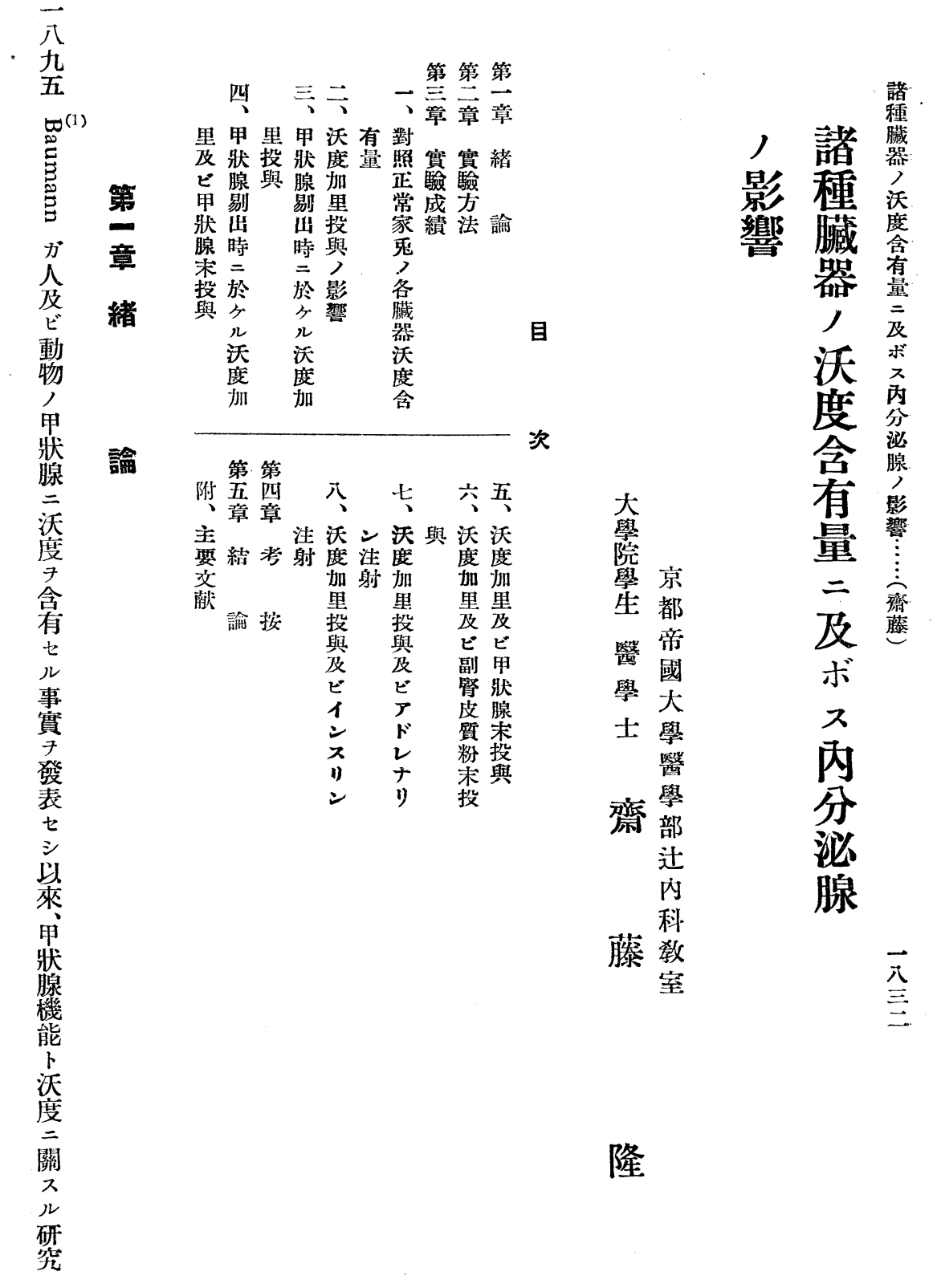




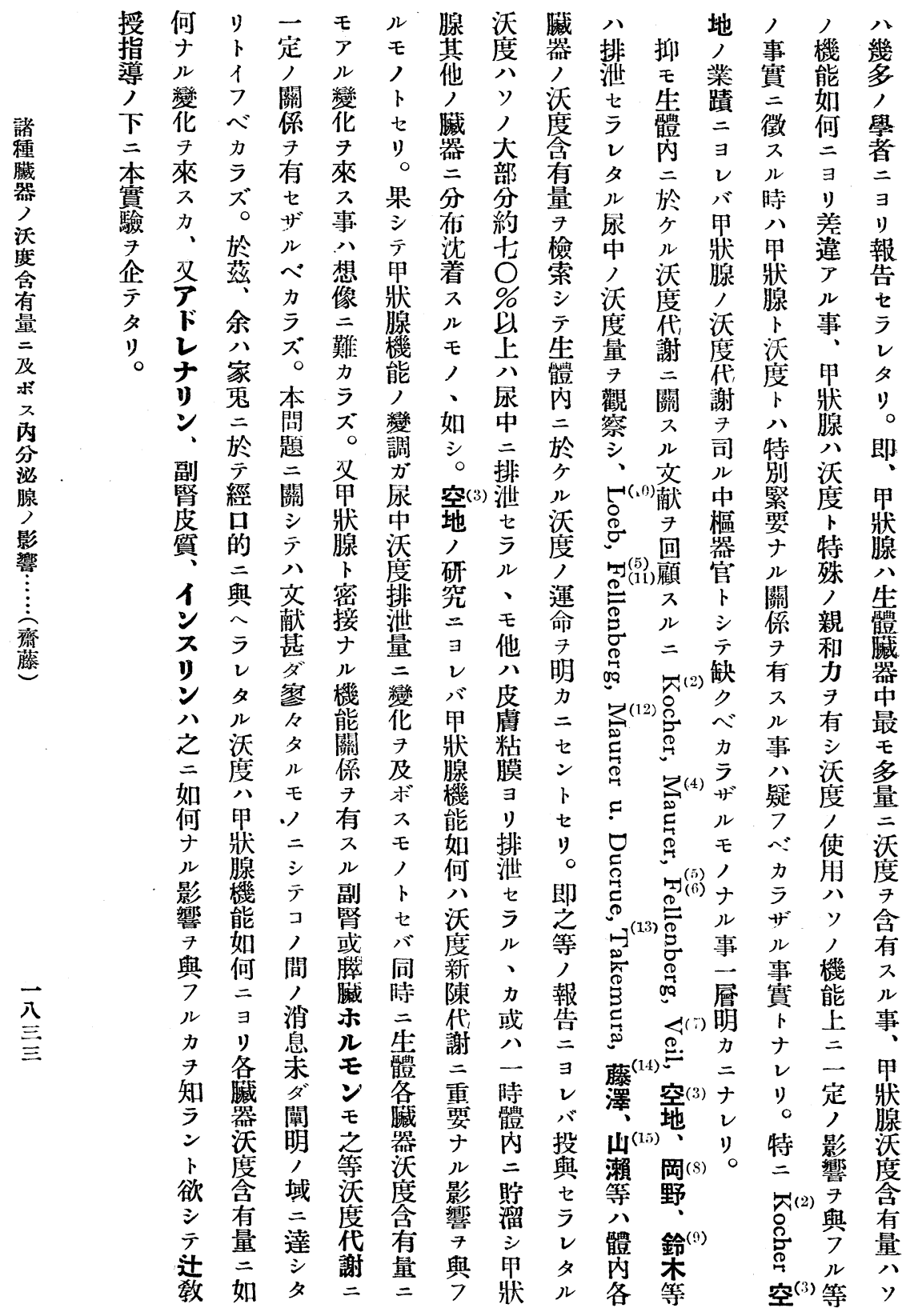




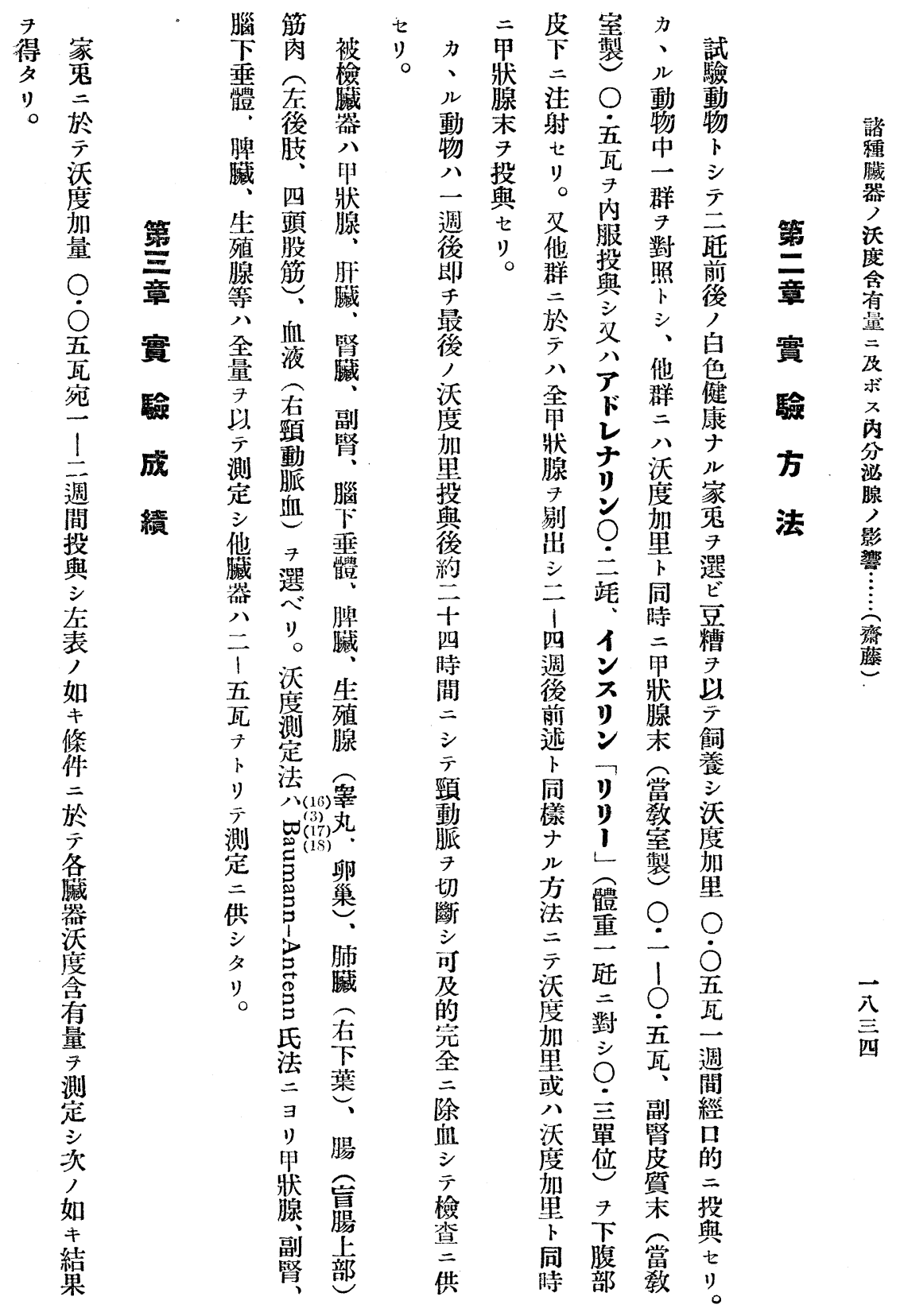




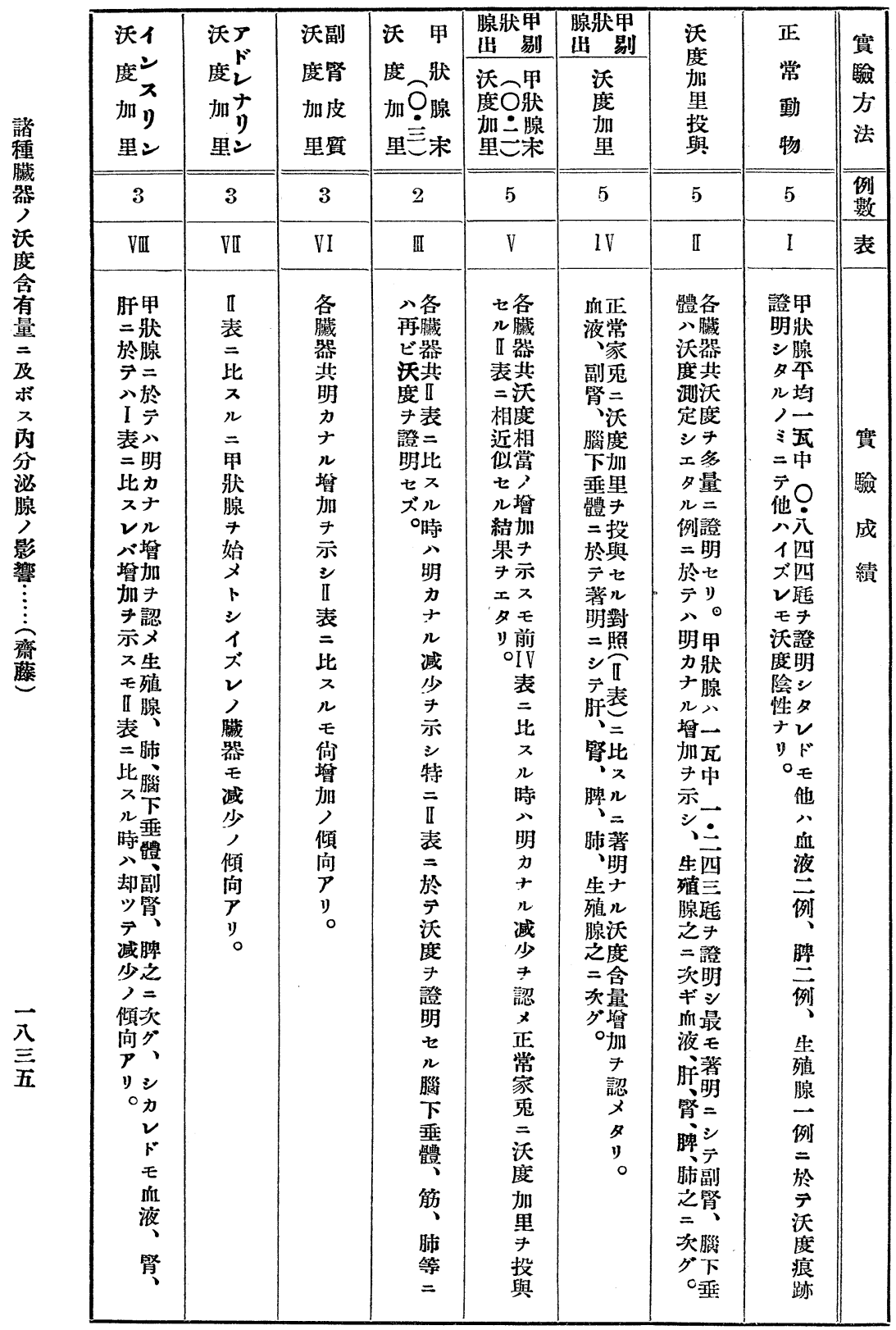




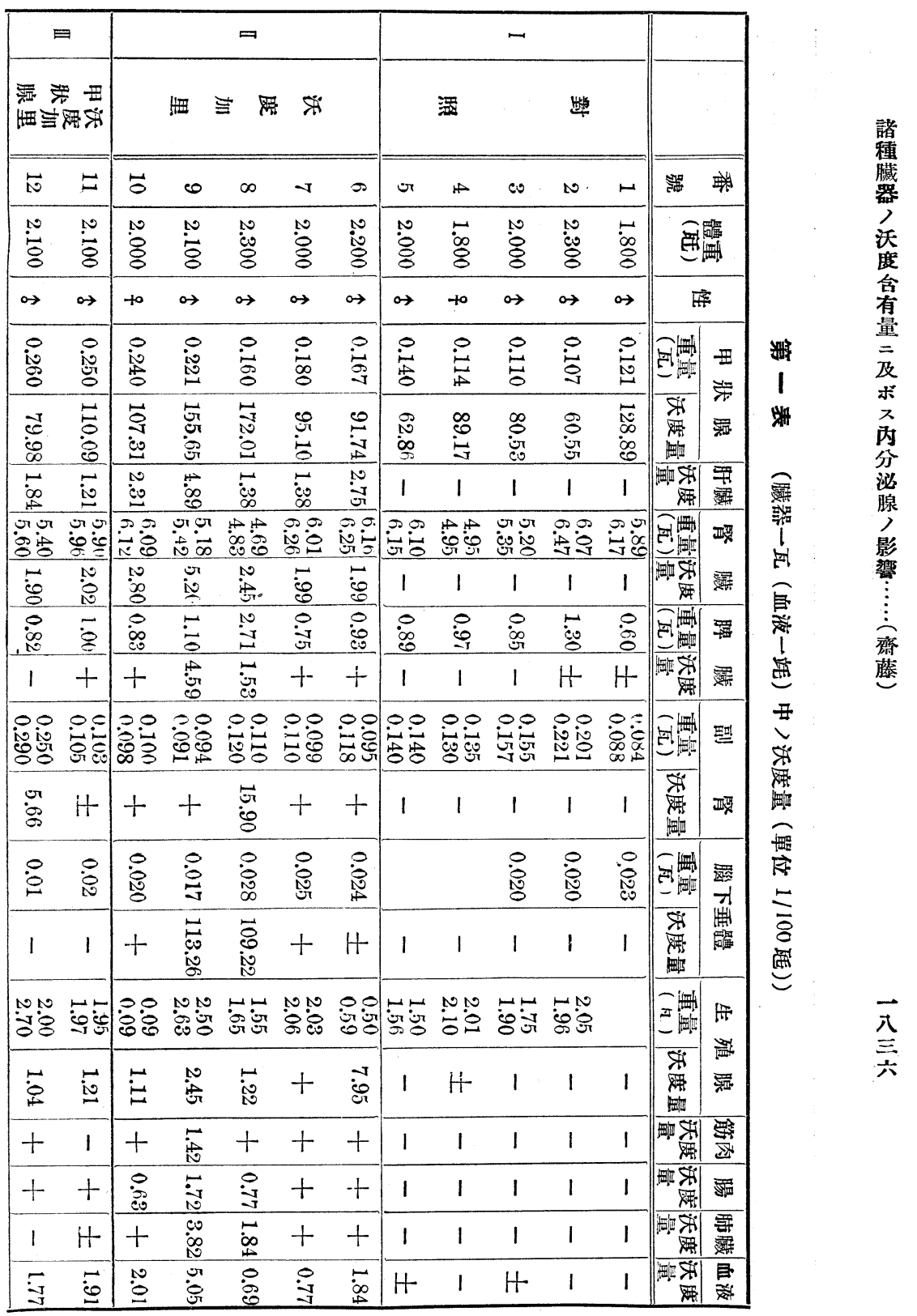




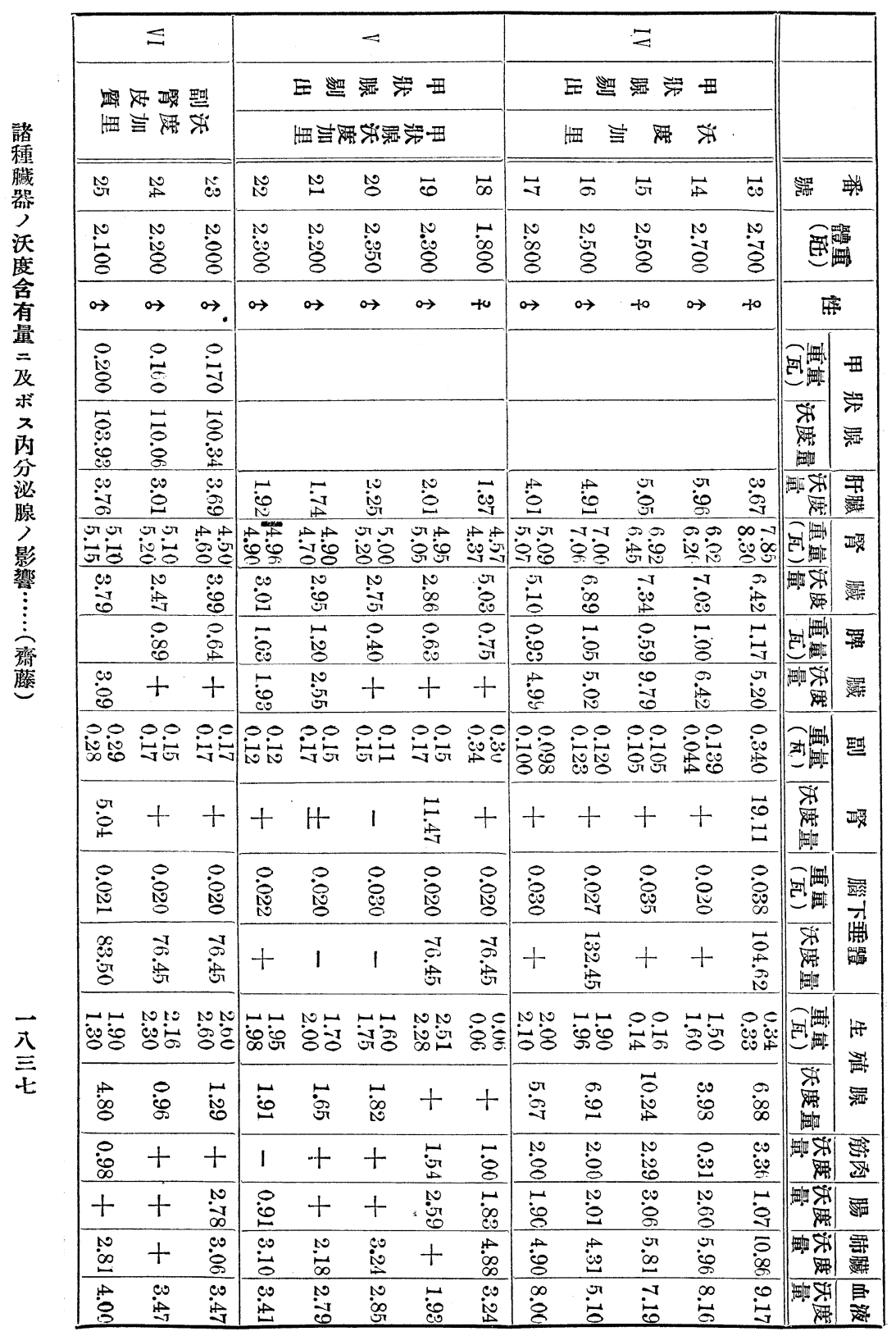




\begin{tabular}{|c|c|}
\hline 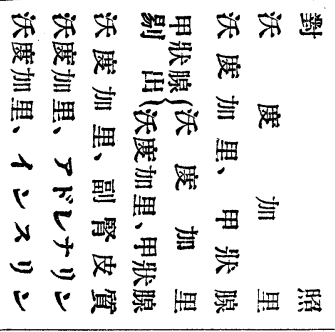 & \\
\hline 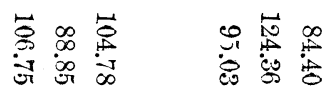 & 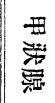 \\
\hline 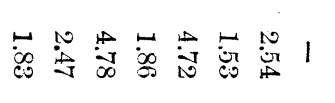 & 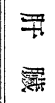 \\
\hline 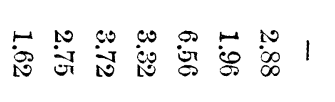 & $\begin{array}{l}\text { 漫 } \\
\text { 路 }\end{array}$ \\
\hline 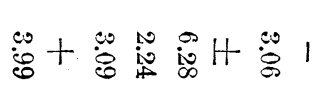 & 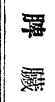 \\
\hline 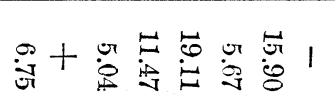 & 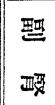 \\
\hline 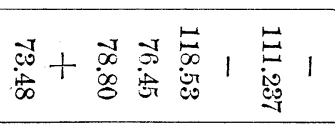 & 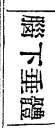 \\
\hline 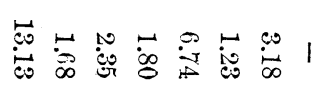 & 霊 \\
\hline 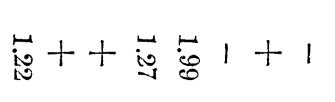 & $\$$ \\
\hline 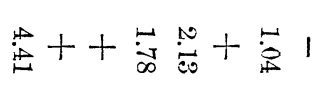 & 震 \\
\hline 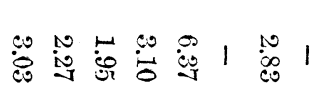 & 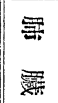 \\
\hline 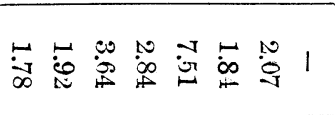 & 急 \\
\hline
\end{tabular}

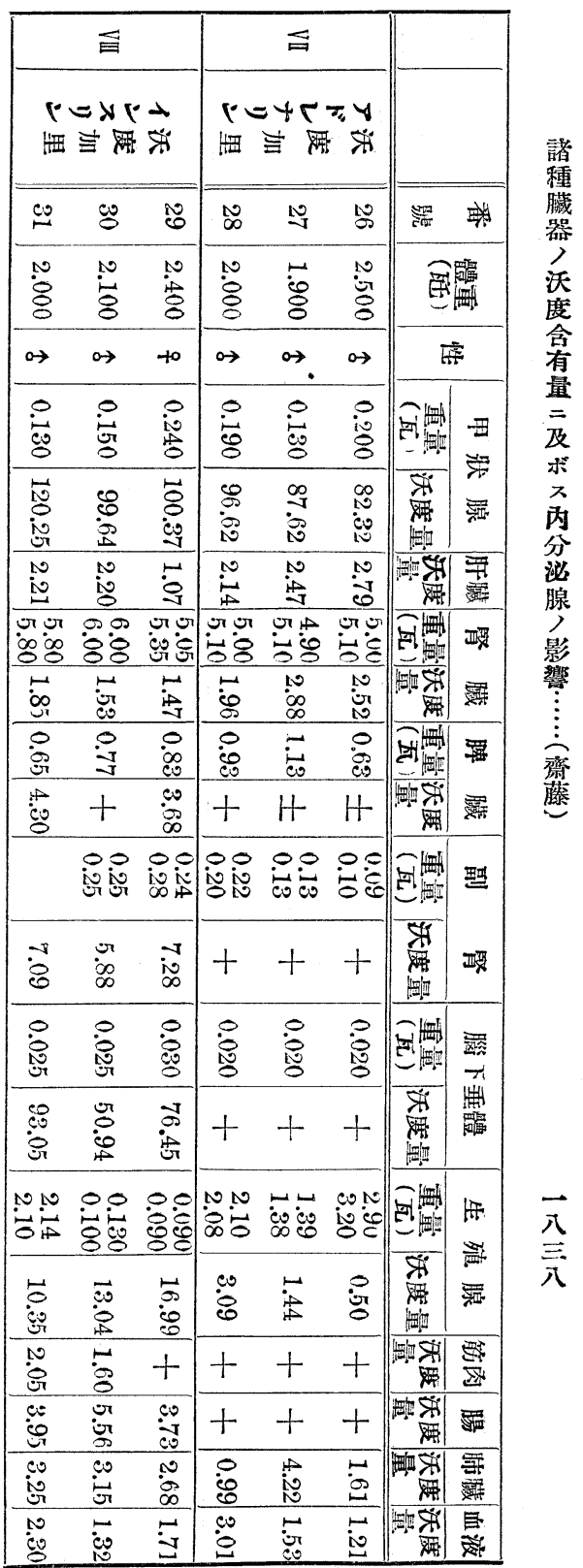



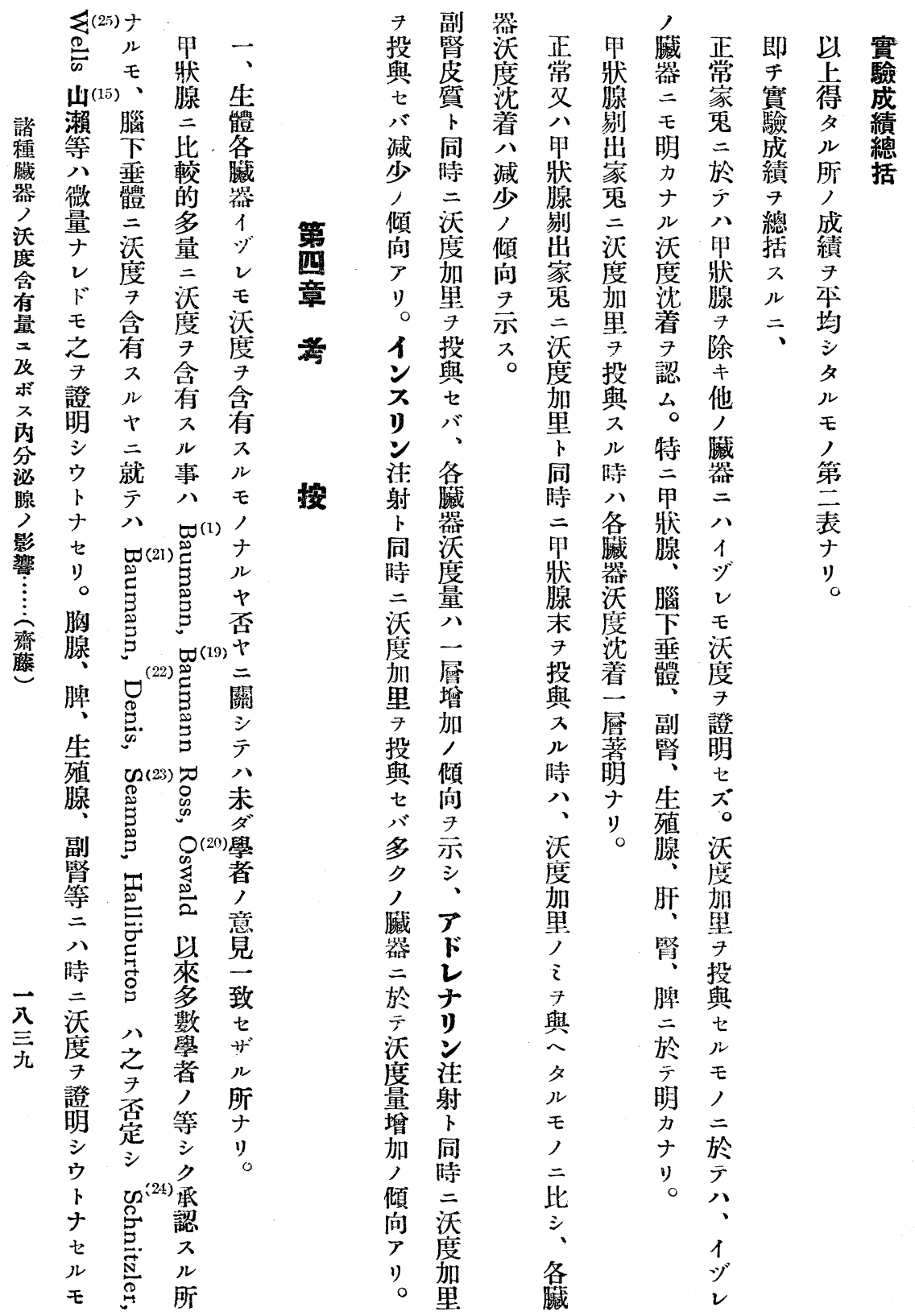


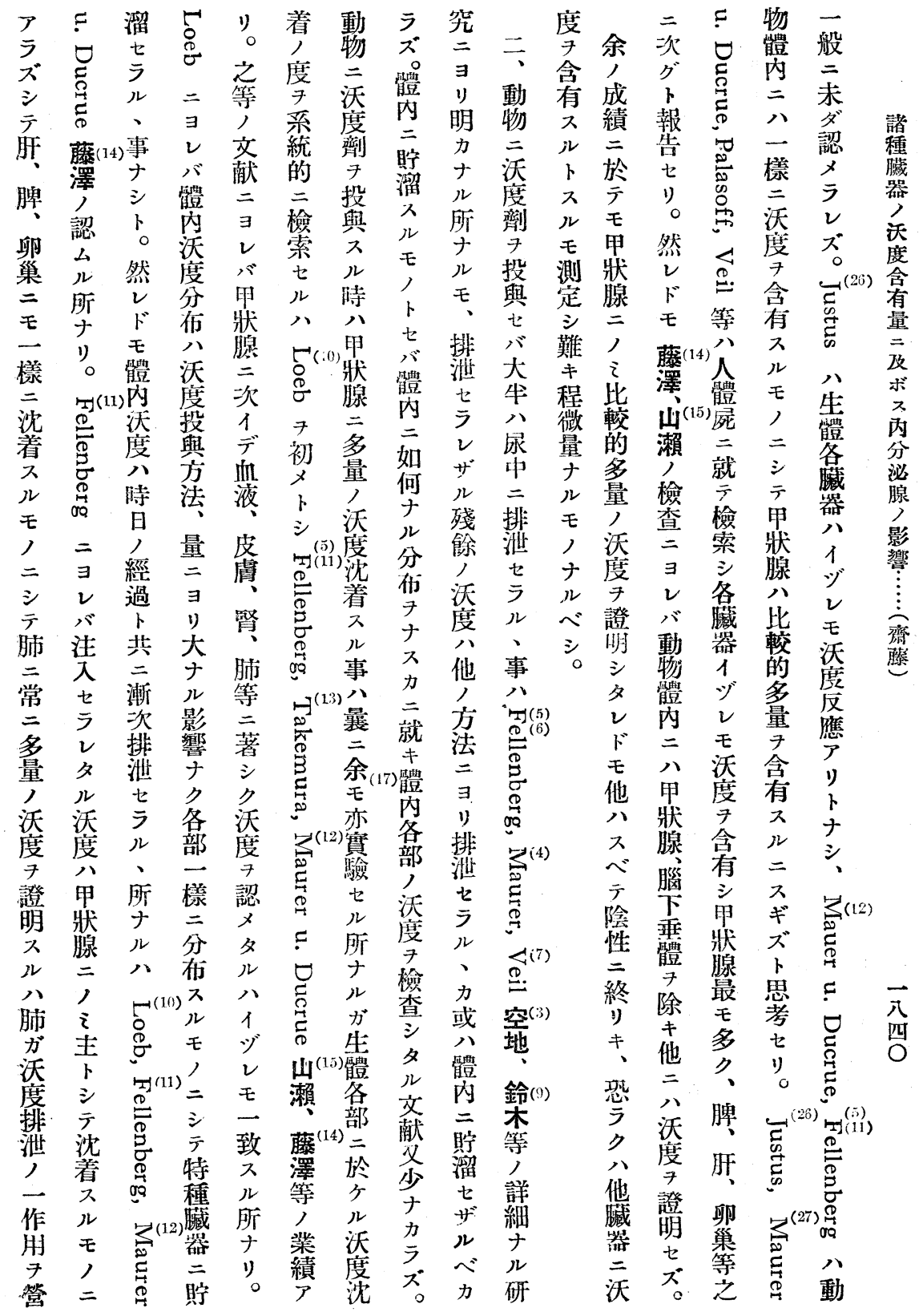




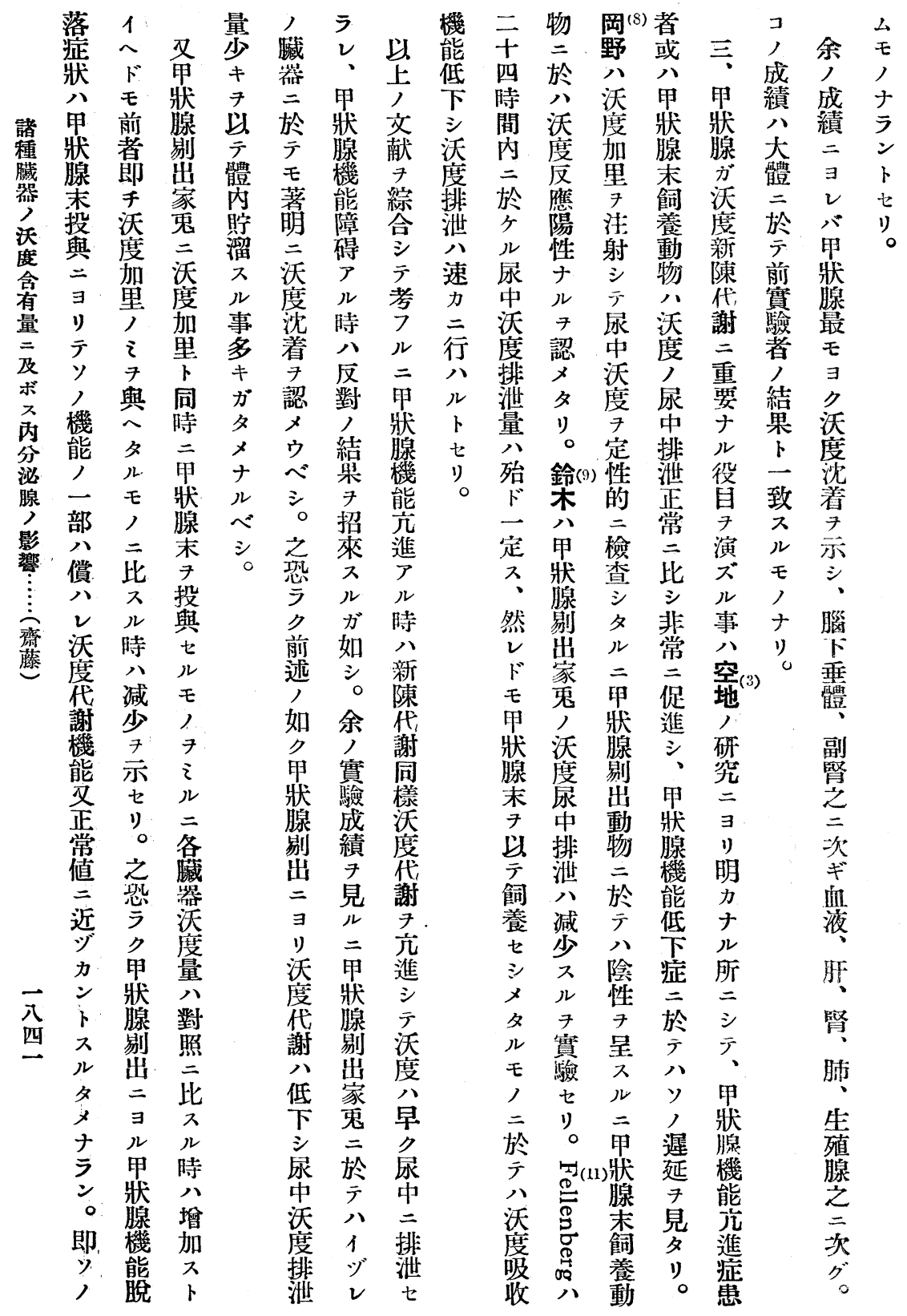




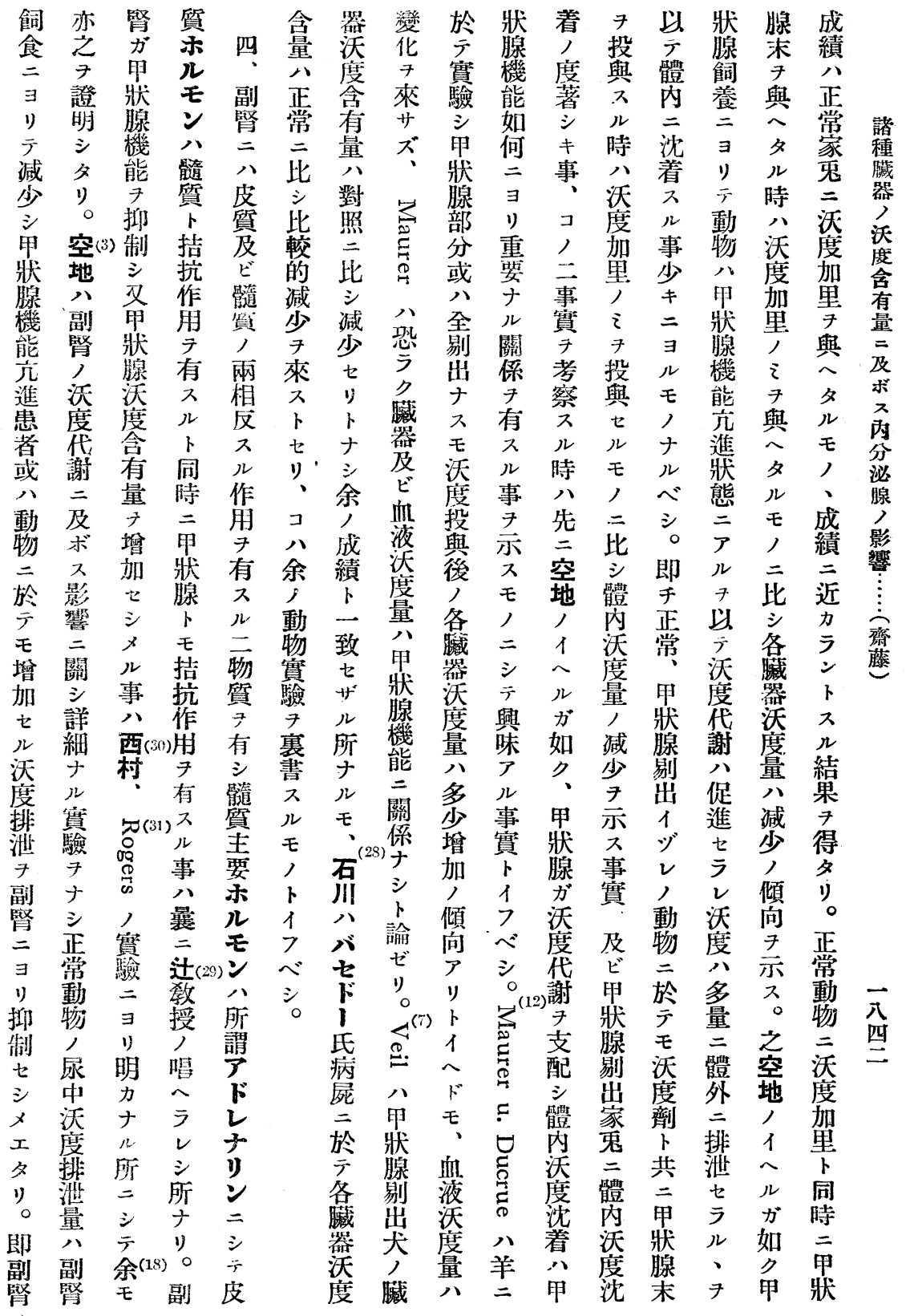




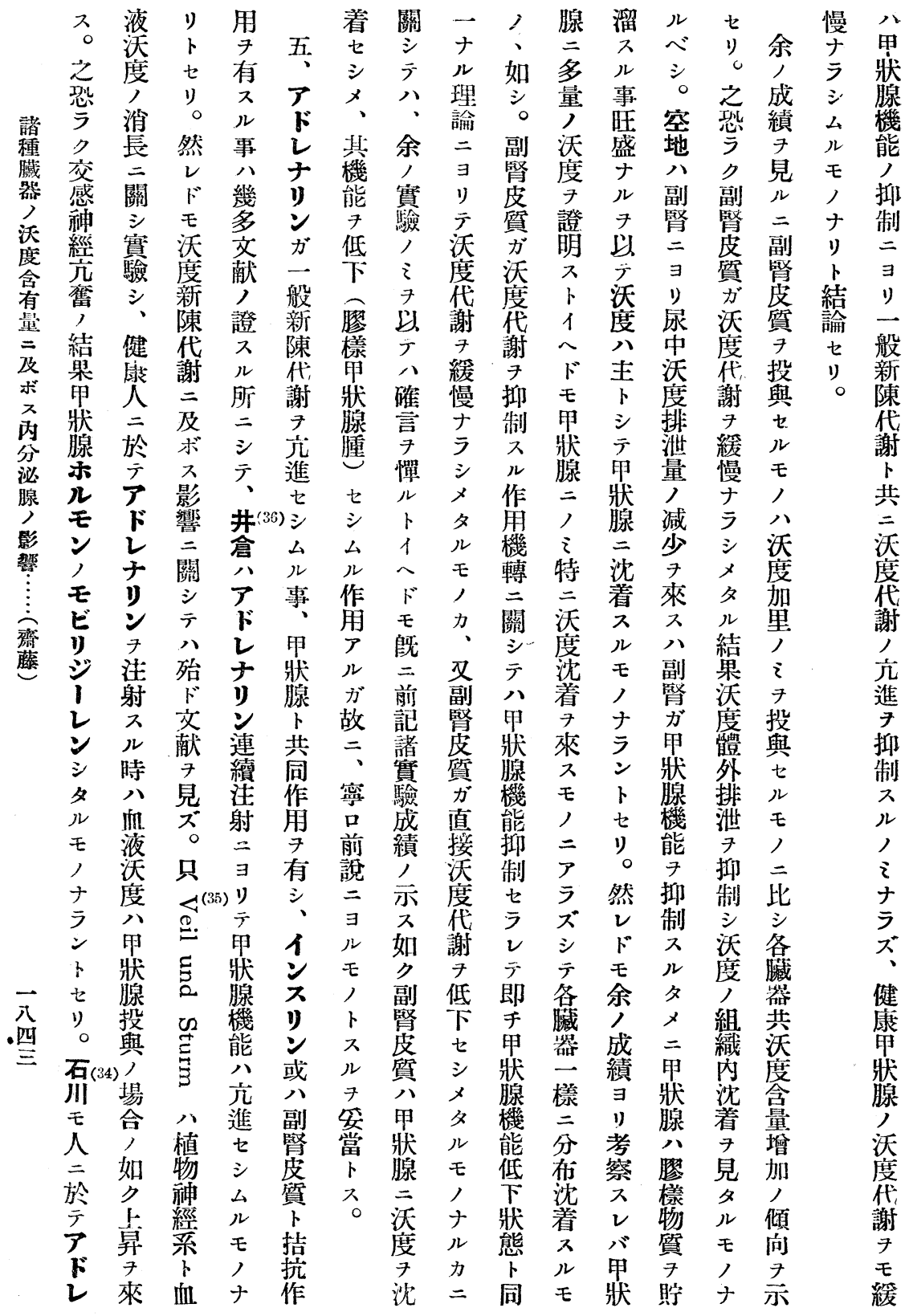




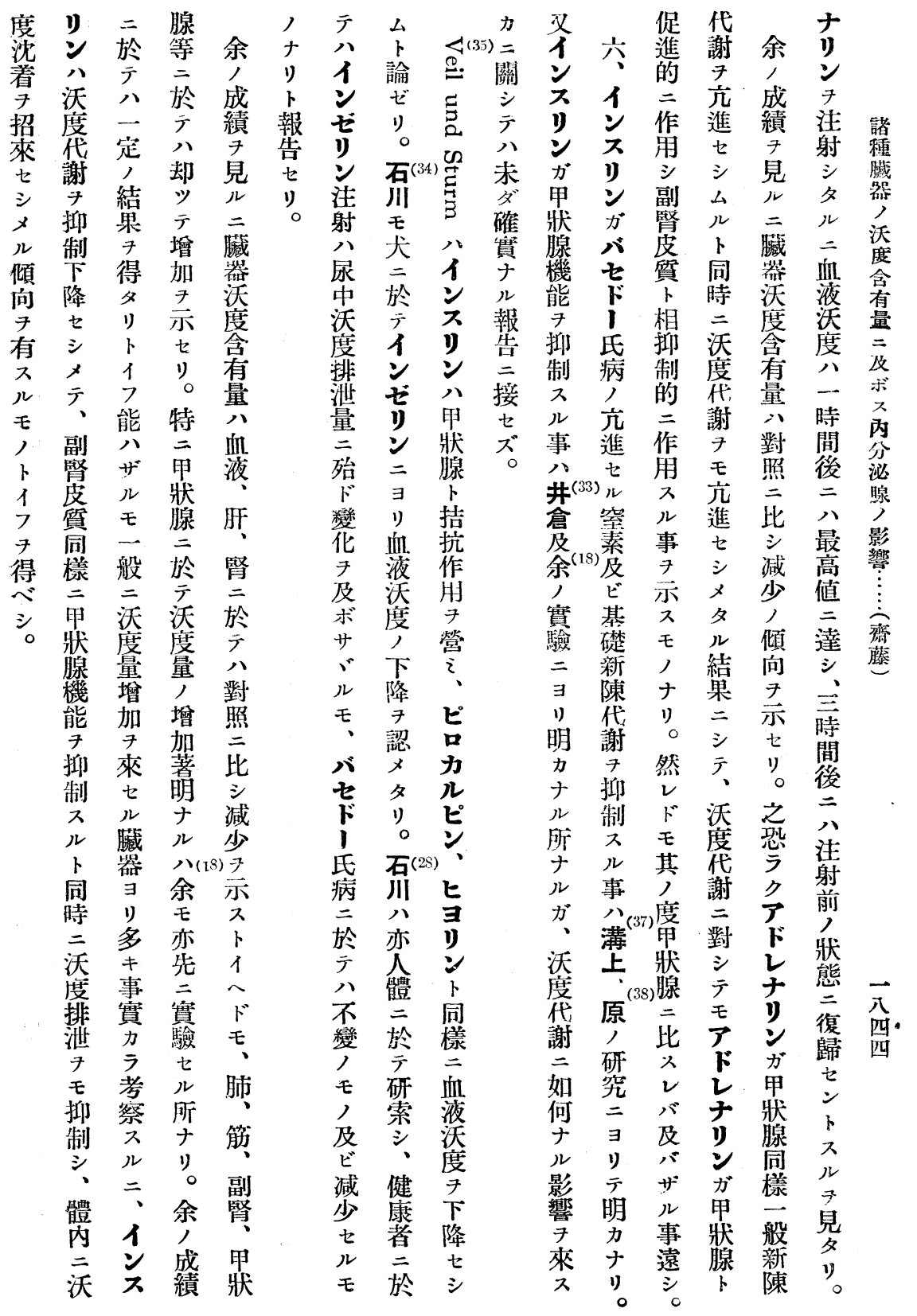




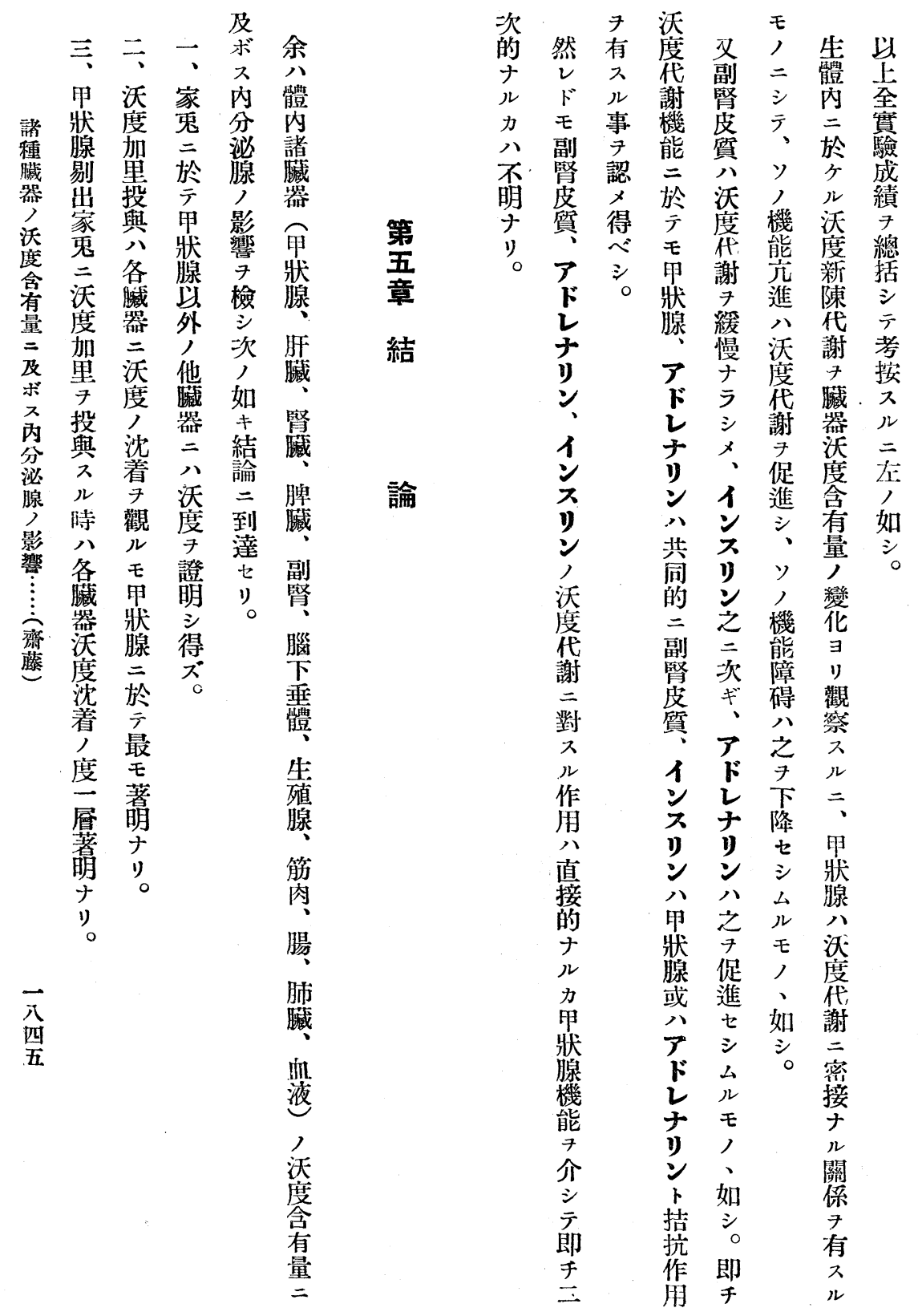




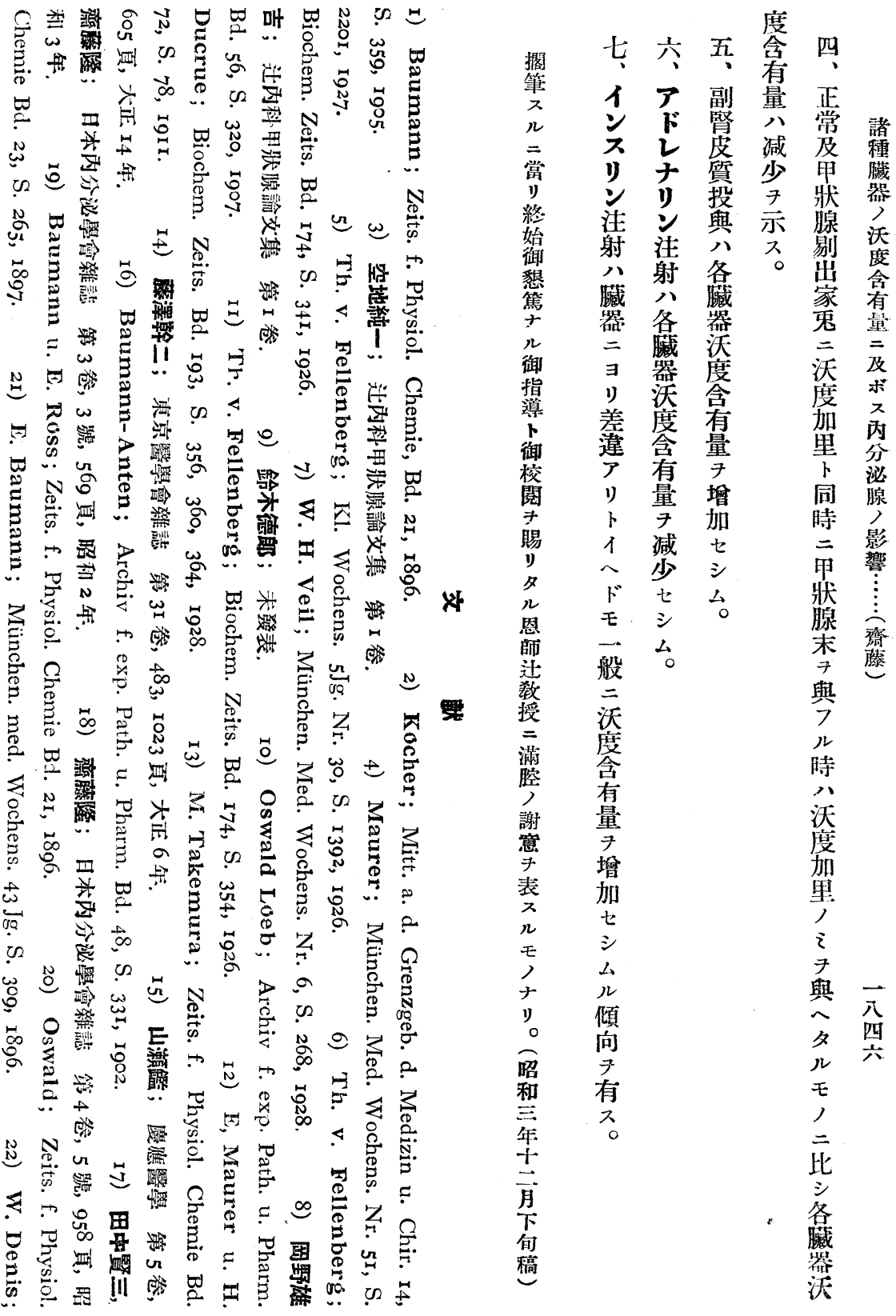




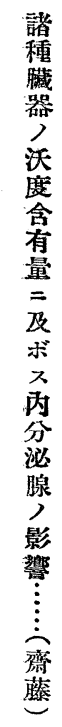

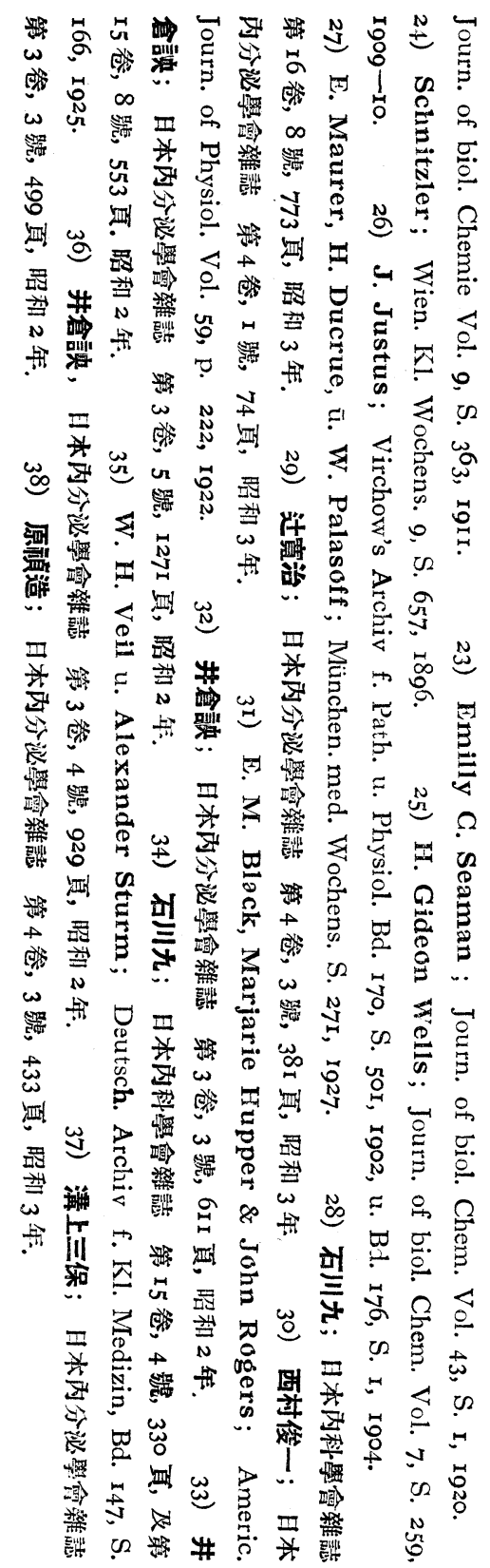


dagegen in Nebenniere und Pankreas, während der Sauerstoffverbrauch der Milz keine Veränderung zeigt.

2. Der Sauerstoff verbrauch der weiblichen kastrierten Tiere vermehrt sich deutlich in der Schilddrüse, weniger in der Nebenniere. In Pankreas und Milz bleibt die Atmung unverändert.

3. In der Leber der kastrierten Tiere beiderlei Geschlechts bleibt der Sauerstoffverbrauch fast unverändert, während sich die Kohlensäureproduktion vermehrt.

\title{
Ueber den Einfluss der innersekretorischen Drüsen auf die Jodverteilung in den tierischen Organen.
}

\author{
Von \\ Dr. T. Saito.
}

(Aus der I. med. Klinik der Kaiserl. Universität zu Kyoto, Japan. Direktor : Prof. Dr. K. Tsuji.)

Der Verf. bestimmte den Jodgehalt nach der BaumannAntenschen Methode in einzelnen Organen von Kaninchen (Schilddrüse, Hypophyse, Nebenniere, Sexualdrüse, Leber, Milz, Niere, Lunge, Darm, Muskel, Blut) nach Verabreichung von Jodkali, nach Einverleibung verschiedener innersekretorischer Drüsensubstanzen oder nach der Schilddrüsenexstirpation.

Die Resultate sind die folgenden:

I. In den meisten Organen ausser der Schilddrüse war kein Jod nachzuweisen.

2. Nach Jodkaliauf nahme (täglich $0.05 \mathrm{~g}$ eine Woche lang) fand sich Jodanhäufung nicht nur in der Schilddrüse, sondern auch in allen anderen Organen, jedoch in grösster Menge in der Schilddrüse.

3. Die Organe zeigten nach Jodverabreichung höheren Jod- 
gehalt bei den schilddrüsenlosen Tieren als bei normalen.

4. Die Jodretention der mit Jodkali und Schilddrüsensubstanzen (täglich $0.05 \mathrm{~g}$ eine Woche lang) gefütterten Tiere war geringer als bei den nur mit Jodkali gefütterten, bei normalen oder der Schilddrüse beraubten Tieren.

5. Die Jodretention nach Jodaufnahme zeigte Zunahme durch Fütterung mit Nebennierenrindensubstanzen (tägl. $0.3 \mathrm{~g}$ eine Woche lang).

6. Die Jodretention verminderte sich durch Adrenalininjektion (tägl. o.rccm eine Woche lang).

7. Bei Insulininjektion (täglich $0.3 \mathrm{kl}$. E. H. per Kilogram K. G. eine Woche lang) zeigte sich Neigung zur Vermehrung der Jodverteilung in den meisten Organen. (Autoreferat)

\section{Ueber die Beziehungen zwischen innerer Sekretion, einigen Pharmaka und Serumanaphylaxie. II. Mitteilung: Ueber die Beziehungen zwischen einigen Pharmaka und der Serumanaphylaxie.}

$$
\text { Von }
$$

Dr. H. Mayeda.

(Aus der I. med. Klinik. d. Kaiserl. Univers. zu Kyoto in Japan. Direktor : Prof. Dr. K. Tsuji.)

Der Verfasser untersuchte an Meerschweinchen die Einwirkungen einiger Elektrolyte und Gifte auf den Anaphylaxieschock.

Die Resultate sind die folgenden:

(I) Die intravenöse Injektion von $3 \%$ iger Chlorcalciumlösung ( $0.5 \mathrm{ccm}$ pro $\mathrm{IOO} \mathrm{g} \mathrm{K}$. G.) ca. 30 Minuten vor der Reinjektion wirkt schutzend gegen den anaphylaktischen Schock, 